\title{
A Flexible Manufacturing Approach to Wood Frame Housing Construction
}

\author{
Michael A. Mullens \\ Department of Industrial Engineering and Management Systems, \\ University of Central Florida, PO Box 162450, Orlando,Florida 32816-2450, USA
}

\begin{abstract}
This paper describes the first installation of advanced CAD/CAM and flexible manufacturing technologies available to U.S. industrialized homebuilders. The production system can produce both interior and exterior wood frame wall panels in an infinite variety of configurations to meet virtually any architectural design need. The paper describes how this production flexibility is gained without sacrificing the benefits of automation. The paper also describes some of the difficulties encountered during system startup including: 1) the difficulty in defining system capacity for advanced production technologies, particularly while allowing almost total design freedom and 2) the difficulty in evolving operations management practices to optimize these advanced technologies. Finally, the paper describes how computer simulation and animation were used to address these issues and provide real system improvement.
\end{abstract}

\section{INTRODUCTION}

Prefabrication has proven to be an effective technique for improving the constructability of many construction projects. ${ }^{1}$ No sector of the U.S. construction industry has been impacted more than housing, where it has been estimated that $50 \%$ of production is industrialized. The most common factory pre-fabricated homebuilding components include roof trusses, wall panels and floor trusses. The advantages of building with these large scale components instead of traditional stick-building on the construction site include: reduced dependence on weather, shortened construction cycle time, higher quality, reduced waste, and, on the bottom line, increased cost effectiveness. Some disadvantages include poor public perception, need for improved planning and coordination, and regulatory problems. 
Most U.S. housing component manufacturers have been conservative in their manufacturing strategy, electing to move manual construction site processes under roof. While capturing some obvious weather-related benefits, this conservative approach has left untapped much of the potential offered by advanced manufacturing technologies such as CAD/CAM and flexible manufacturing. ${ }^{2,3}$ Meanwhile, international homebuilders in Scandinavia and Japan have been more aggressive, producing a substantial percentage of their housing in highly automated factories., 4 However, much of this computer integration and automation has come at the expense of design flexibility. For example, one automated factory in Finland is limited to 54 configurations of a wall panel. Conventional wisdom in the industry is that the U.S. housing market will not accept the design limitations commonly associated with automation.

In response, equipment suppliers have developed a new generation of production systems specifically for the U.S. housing market. The Makron Wall Panel Line is arguably the first practical application of advanced CAD/CAM and flexible manufacturing technologies available to U.S. industrialized homebuilders. ${ }^{6}$ It can produce both interior and exterior wood frame panels in an infinite variety of configurations to meet virtually any architectural design need. The line is a true $\mathrm{CAD} / \mathrm{CAM}$ system. CAD software is linked by local area network (LAN) to the line's programmable logic controller (PLC), which drives both assembly and material handling equipment. The line's computer integration and cost effective automation combine to provide square and accurate framing in a highly efficient, paperless, continuous production operation.

This paper describes the first installation of the Makron Wall Panel Line and some of the difficulties encountered during system startup including: 1) the difficulty in defining system capacity for advanced production technologies, particularly while allowing almost total design freedom and 2) the difficulty in evolving operations management practices to optimize these advanced technologies. The paper also describes how computer simulation and animation were used to address these issues and provide real system improvement.

\section{Line Configuration and Operation}

The first Makron Wall Panel Line was installed in 1994. It was designed to produce both interior and exterior wall panels. Builders used these panels to construct two-story homes ranging from 2,000 to 3,500 square feet. These homes typically sell for $\$ 150,000$ to $\$ 400,000$. When a builder orders components for a home, the design staff translate architectural drawings into accurate CAD representations (Figure 1) of manufactured wall panels. A typical house is constructed from 100 wall panels, equally divided between interior and exterior. Most panels in a home are unique and even standard house plans are highly customized. Panels range from 1' to 12 ' in length, from 4' to 12 ' in height, and use either $2 \times 4$ " or $2 \times 6 "$ dimensional lumber. 


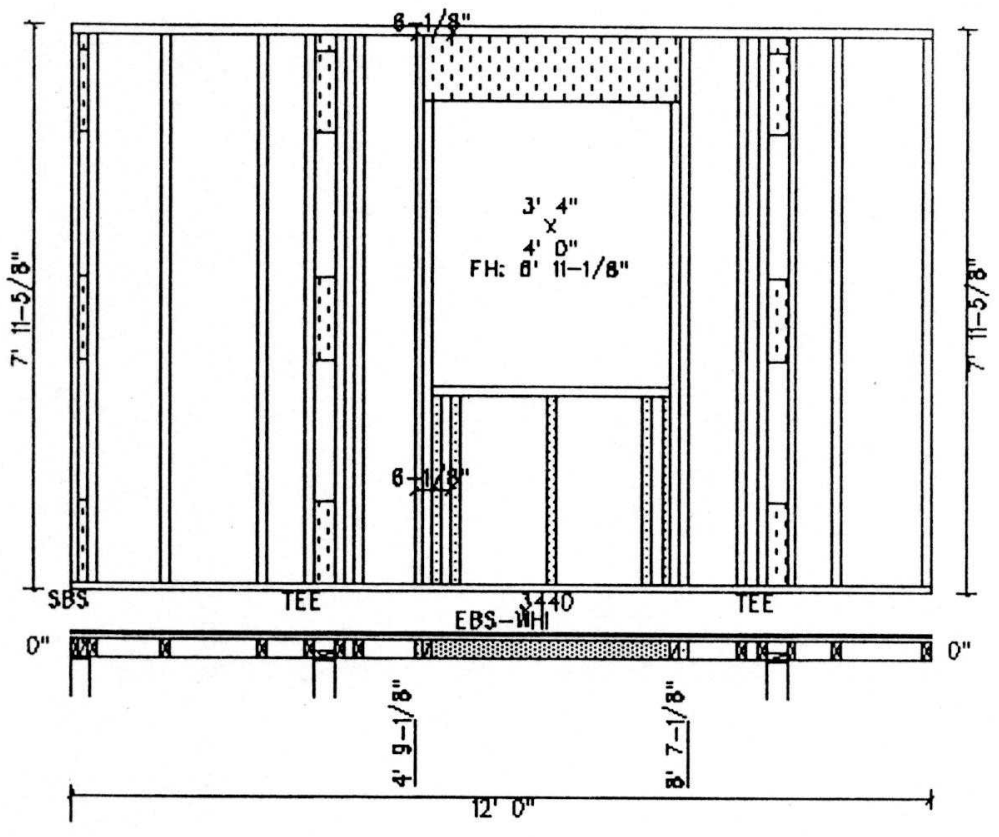

Figure 1 Typical CAD Representation of Panel Design
The CAD system a u t o m a tically sequences panels for production in the reverse sequence of assembly on the construction site. Operators cut and sub-assemble panel components manually in off-line stations, using batched instructions printed by the CAD system. Figure 2 shows the beginning of the line. On the right two operators are using a specialized jig table to frame window, door and fireplace opening

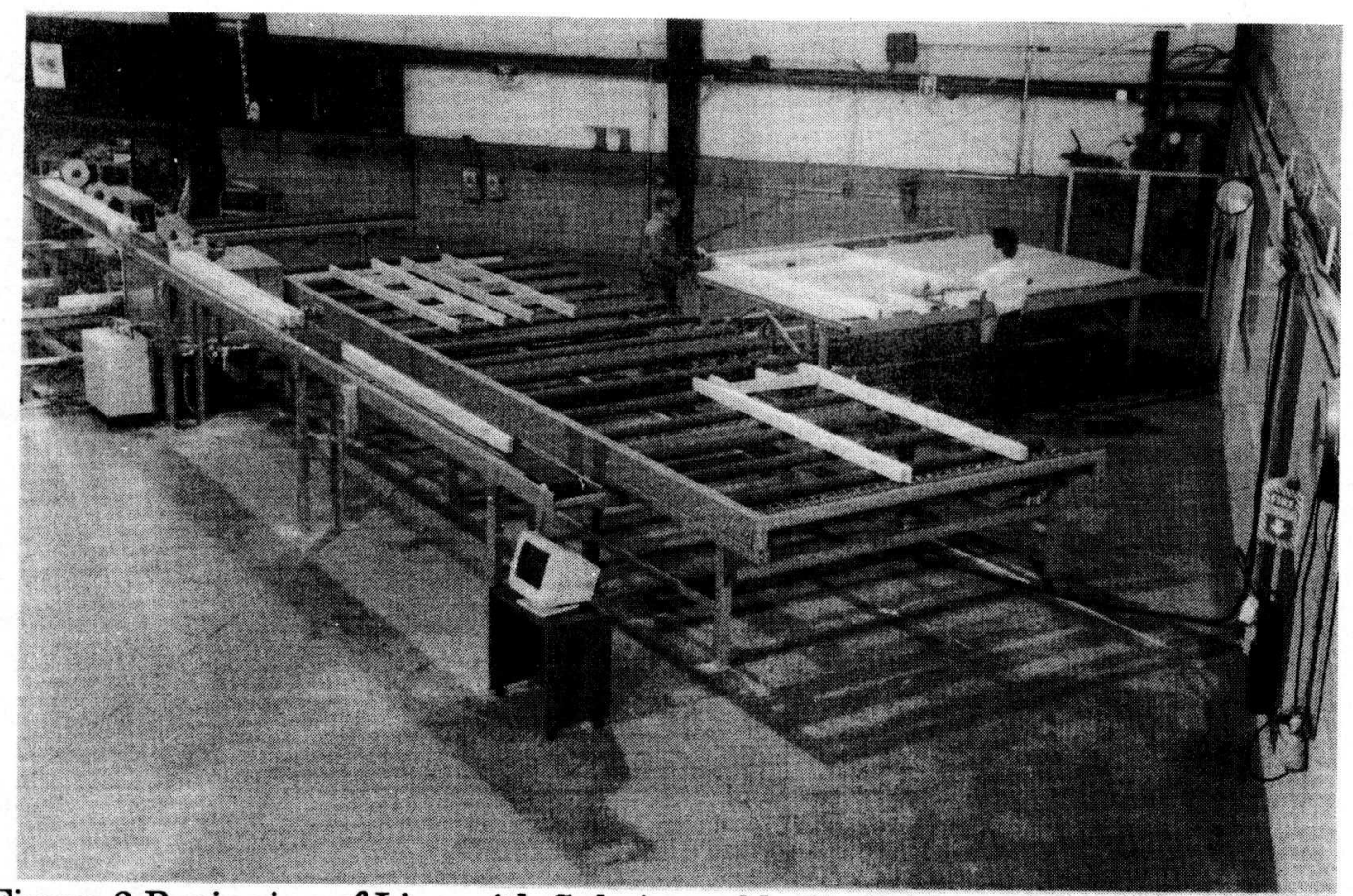

Figure 2 Beginning of Line with Sub-Assembly Jig Table and Feed Conveyors 


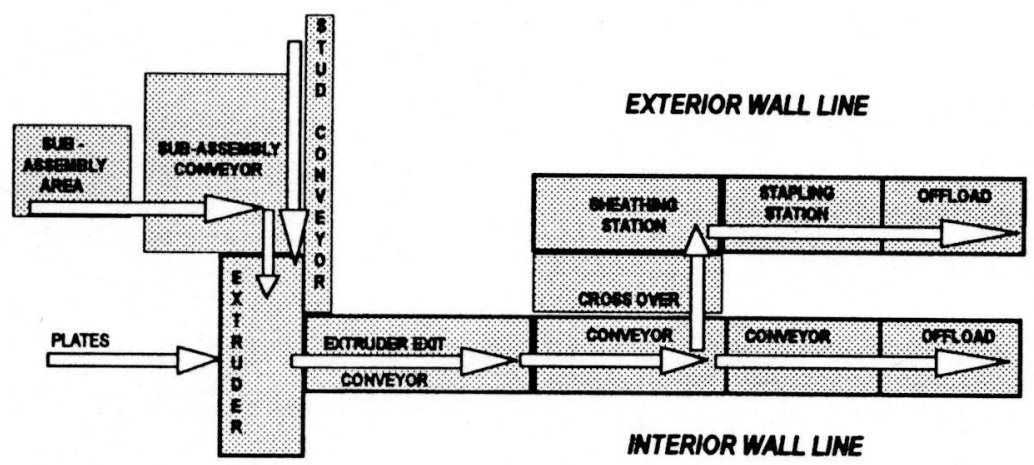

Figure 3 Schematic of Wall Panel Line

sub-assemblies. After framing, sub-assemblies are placed on the large feed conveyor shown in the center for transport to framing. Operators place studs (vertical framing members) on the narrow conveyor on the left as directed by the on-line display.

A schematic of the overall line is shown in Figure 3. Components flow to the extruder (Figure 4) for framing with top and bottom plates (horizontal framing members). The on-line display directs the extruder operator to retrieve the proper component and position it for framing. The extruder automatically clamps the component and nails both top and bottom ends. A clamping bridge then pulls the panel forward for the next component or, if complete, pulls it clear of the extruder.

Interior panels are complete when they leave the extruder and flow directly to

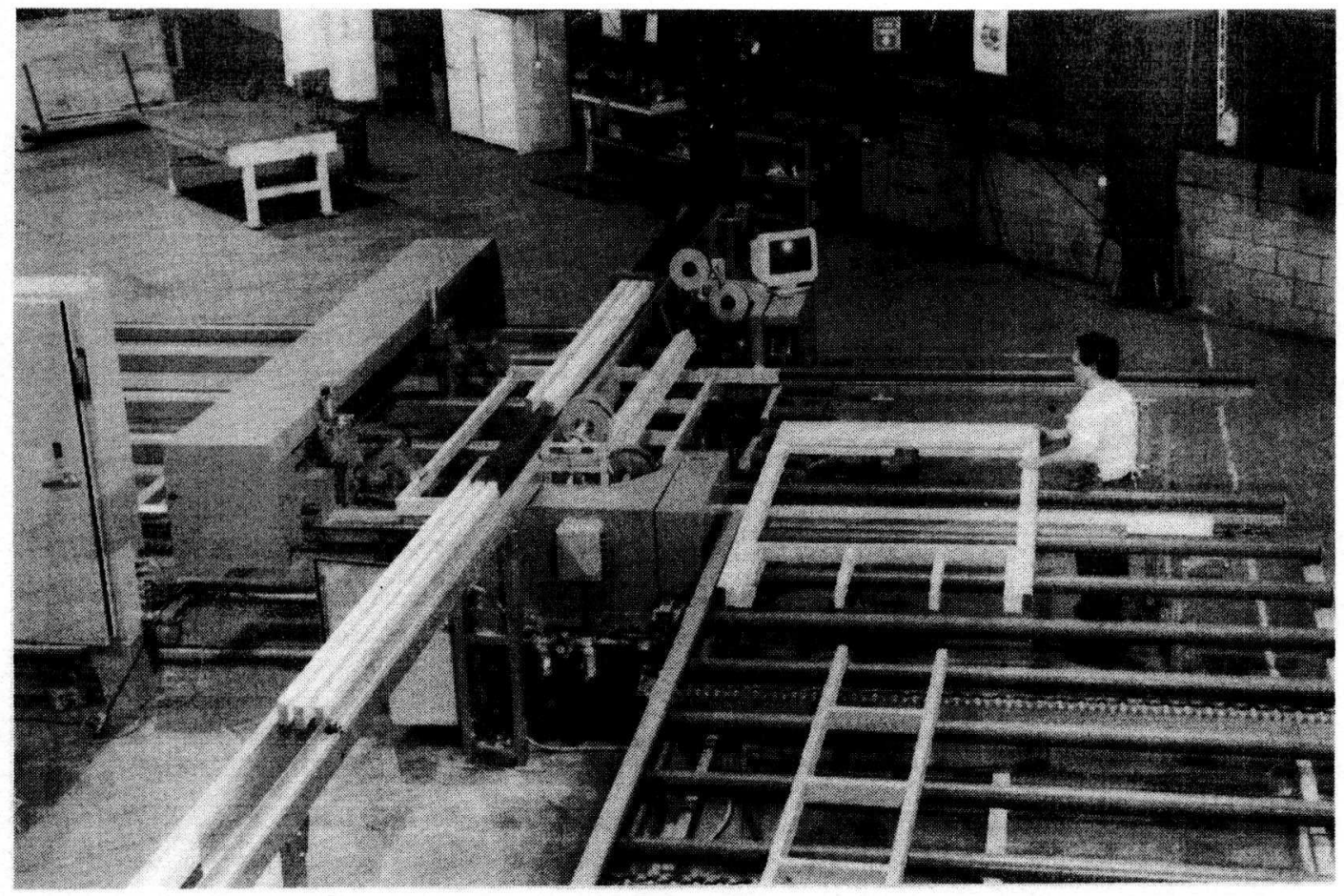

Figure 4 Extruder Station 


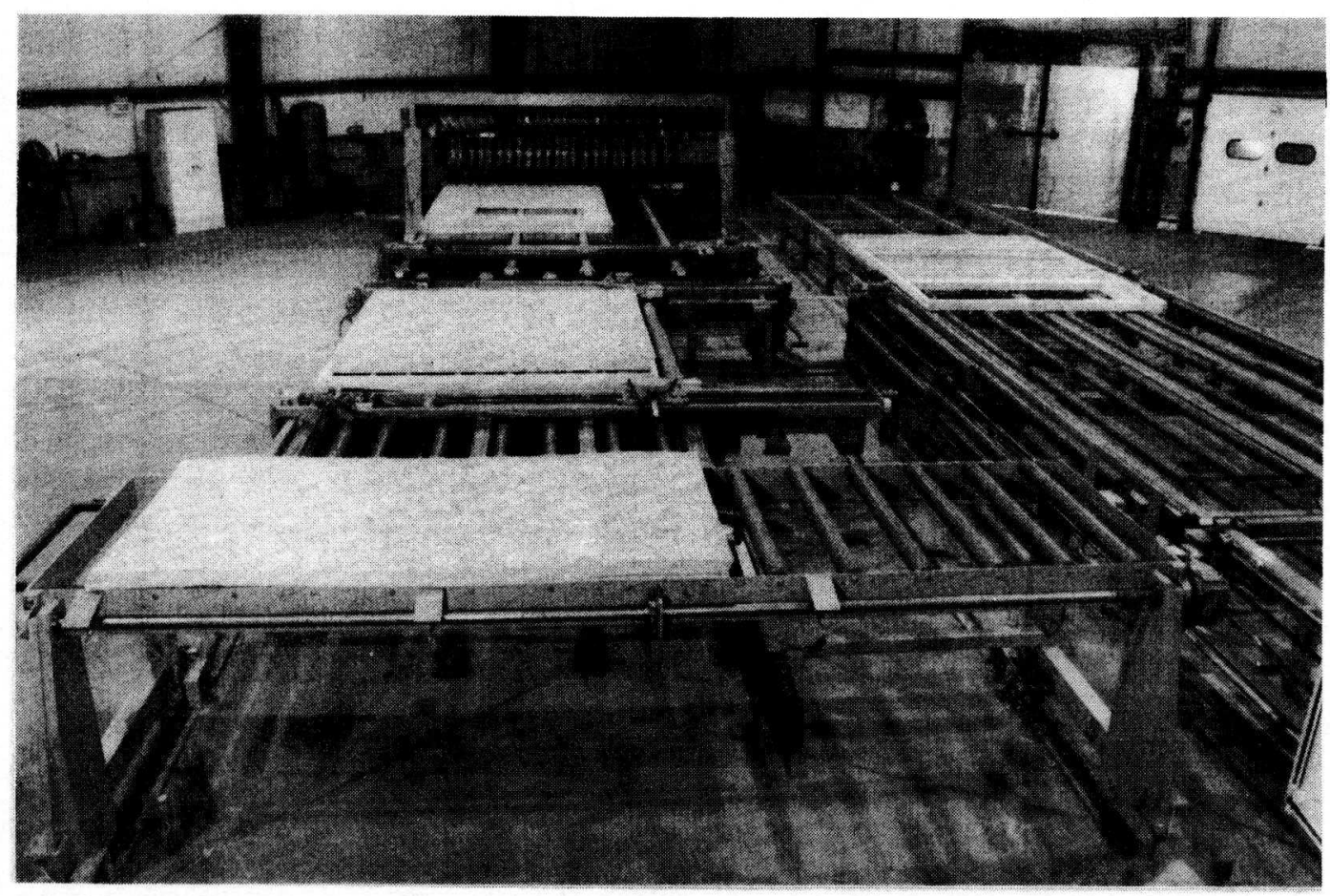

Figure 5 Downstream Line Operations

the interior wall line offload position. The interior wall line is shown on the right in Figure 5, with the offload position at the top. A two person offload team palletizes all panels. Exterior panels cross over to the exterior wall line (shown on the left) where sheathing ("skin") is applied and stapled to the exterior side of the skeletal panel. In the sheathing station (shown in the center) the system automatically clamps and squares the panel while two operators apply and tack the sheathing. Operators stage sheathing on a sheathing supply bridge (shown at the bottom) which automatically positions itself at the edge of the panel. After operators retrieve the necessary sheathing from the bridge, they release the bridge to return to its home position. After tacking is complete, the panel is released for transport to the stapling station shown at the top. In the stapling station, the system again automatically clamps and squares the panel and activates a nailing bridge, which automatically staples the sheathing as specified by local building codes. After stapling, the nailing bridge indexes to its home position, allowing the panel to be offloaded.

\section{Start-up Difficulties and Resolution}

As is common with new, highly integrated manufacturing systems, the line experienced start-up problems. Two critical problems were: 1) the difficulty in 
defining system capacity for advanced production technologies, particularly while allowing almost total design freedom and 2) the difficulty in evolving operations management practices to optimize these advanced technologies. The Energy Efficient Industrialized Housing (EEIH) research team assisted the component manufacturer under the U.S. Department of Energy's (DOE) innovative Process and Energy Efficiency Review (PEER) outreach program, which provides technical support to industrialized housing manufacturers interested in upgrading their products and processes. Due to the complexity of the system and the dynamic nature of the problem, the team used a computer simulation approach. Mullens et al have described the use of simulation in addressing similar problems. ${ }^{7}$

The model was developed at the manufacturer's factory on a 486 laptop PC using ProModel for Windows ${ }^{\mathrm{TM}}$, a manufacturing simulator featuring an object oriented graphical user interface and extensive custom programming constructs. ${ }^{8}$ Previous EEIH research had resulted in the development of higher level constructs for modeling panel manufacturing operations. ${ }^{7}$ The team used pre-coded modules from this earlier effort as a starting point to simplify model development. The team used an EXCEL ${ }^{\mathrm{TM}}$ spreadsheet for production order input. To improve model realism, the team overlaid the animation over the background of an artist's rendering scanned from the supplier's brochure (Figure 6). Custom product icons

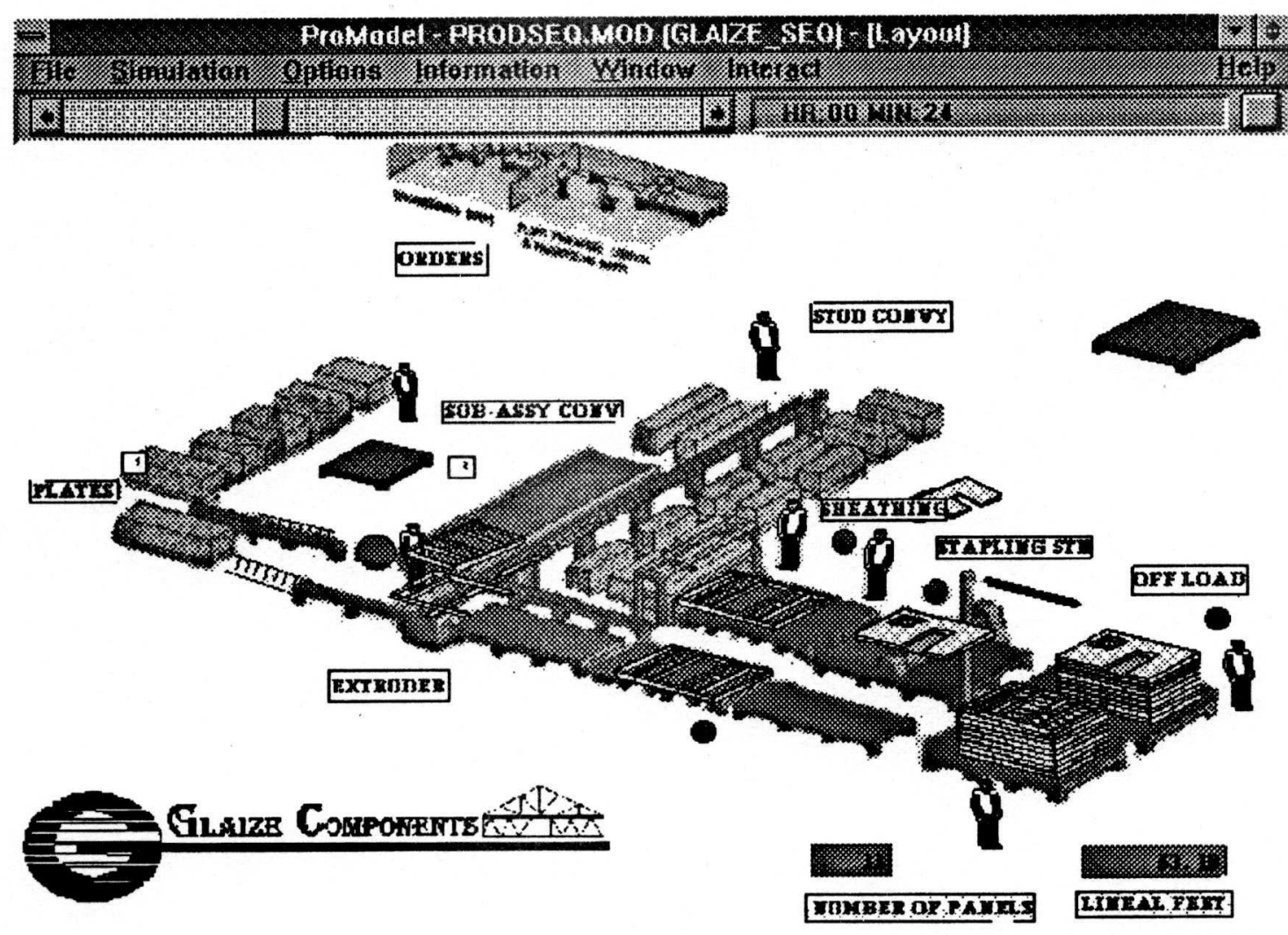

Figure 6 Animation for Computer Simulation Model 
were created in the same perspective as the rendering. To highlight suspected problems, the team created location status indicators for select line components. Finally, the team provided "running" production totals similar to those used by management to monitor line performance.

The simulation modeling and analysis suggested that the production sequence was the most obvious factor affecting line capacity. The line's control system software automatically sequenced panels in reverse construction site assembly sequence. While this reverse assembly sequence was ideal from a builder's perspective (and satisfactory for the old manufacturing process), it created problems for the new panel line. The strategy sequenced all exterior panels for each floor before the associated interior panels. This resulted in severe bottlenecks when manufacturing exterior panels. Since downstream (sheathing and stapling) process times were often longer than upstream (extruder) times, bottlenecks formed. These bottlenecks eventually blocked the crossover position and caused delays at the extruder, resulting in lost line capacity.

To remedy the problem, the team recommended a production sequence which alternated exterior and interior panels for each floor of the house. Since the line configuration permitted two pallets to be stacked simultaneously (one containing interior panels and the other exterior panels), panels were still available in the optimal sequence for the builder. Simulation analysis indicated that re-sequencing could increase system capacity by $8 \%$. The team also simulated several less successful "alternating sequence" scenarios. There results offered some important insights regarding line performance:

1. There are seldom equal numbers of interior and exterior panels in an order. In the worst case a builder may purchase only exterior panels. Line capacity will be reduced accordingly.

2. We must exercise caution as we alternate between interior and exterior panels. Each time we alternate between panels with different heights, we incur a substantial setup time at the extruder, losing the desired advantage.

3. Sheathing station operators worked on off-line operations whenever a series of interior panels were being produced. When using an alternating sequence, operators cannot leave the station.

\section{CONCLUSIONS AND FUTURE RESEARCH}

After reviewing the simulation results, the component manufacturer tried the new sequencing strategy. The change has yielded a $7-10 \%$ increase in line capacity with minimal increases in labor and capital. The additional sequencing flexibility did require some control system software changes. The simulation has also provided important insight for prioritizing future capacity improvement efforts. Other issues which might be addressed through the simulation model include: incorporation of current off-line operations into the line through Just In Time (JT) production techniques, more effective sequencing strategies to achieve better line 
smoothing, and improved product costing.

From an industry perspective, it is absolutely critical that the industry and its suppliers understand the important role of modeling in supporting the introduction of advanced process technologies. This is important for two reasons. First, the complexity of the new systems coupled with the flexibility demanded of the product make it difficult, if not impossible, to estimate system capacity without modeling techniques. Second, the established operations management paradigms, such as the "reverse assembly sequence" scheduling rules, must be challenged to assess their relevance when using advanced process technologies.

\section{ACKNOWLEDGMENTS}

This research was sponsored by the United States Department of Energy, through the Energy Efficient Industrialized Housing (EEIH) research program. The EEIH program is jointly conducted by the Center for Housing Innovation, University of Oregon, the Florida Solar Energy Center and the Department of Industrial Engineering and Management Systems, University of Central Florida. (DOE Contract No. DE-FC03-89SF17960)

\section{REFERENCES}

1. Tatum, C., Vanegas, J. and Williams, J. 1987, Constructability Improvement Using Prefabrication, Preassembly, and Modularization, Source Document 25, The Construction Industry Institute, Austin, Texas.

2. Bedford, D., Henderson, M. and Wolfe, P. 1991, Computer-Integrated Design and Manufacturing, McGraw-Hill, Inc., New York, NY.

3. Nyman, L. 1992, Making Manufacturing Cells Work, Society of Manufacturing Engineers, Detroit, MI.

4. Kando, P. 1988, When the Best Costs Less: An Economic Comparison of the Swedish Factory Crafted House Construction System and Conventional Homebuilding, Center for the House, Washington, D.C.

5. McKellar, J. 1985, Industrialized Housing: The Japanese Experience, Alberta Municipal Affairs, Edmonton, Alberta.

6. Makron Wall Panel Line 1994, Makron U.S. Inc., Clifton Park, NY.

7. Mullens, M., Armacost, R. and Swart, W. 1995, "The Role of Object Oriented $\mathrm{CAD}$ in a Generic Simulator for the Industrialized Housing Industry,"Automation in Construction, Vol. 4, No. 1, pp. 29-43.

8. ProModel for Windows ${ }^{T M}$ User's Guide, Version 2.0 1994, ProModel Corporation, Orem, UT.

9. Microsoft ${ }^{T M} E X C E L^{T M}$ User's Guide, Version 5.0 1994, Microsoft Corporation, Redmond, WA. 